\title{
Basaloid Adenoma of Nasal Pits: Rare Location with Atypical Clinical Presentation \\ Najoua. Belhaj ${ }^{1,3 *}$, Ikram.Boumendil ${ }^{2}$, Hajar. Ait Taleb Oumhand ${ }^{2}$, Hanaa. Rahim², Razika. Bencheikh ${ }^{2}$, Mohammed.Anass. Benbouzid $^{2}$, Leila. El Houssyni Essakalli ${ }^{2}$
}

${ }^{1}$ Resident physician in Otorhinolaryngology, Department of Otorhinolaryngology, Head and Neck Surgery, Ibn Sine University Hospital, Rabat, Morocco

${ }^{2}$ Professor of Otorhinolaryngology, Department of Otorhinolaryngology, Head and Neck Surgery, Ibn Sine University Hospital, Rabat, Morocco ${ }^{3}$ Faculty of Medicine and Pharmacy of Rabat, Mohammed V University, Rabat, Morocco

DOI: $10.36347 /$ sjmcr.2021.v09i02.002

| Received: 18.01.2021 | Accepted: 02.02.2021 | Published: 03.02.2021

*Corresponding author: Najoua. Belhaj

\section{Abstract}

Basal cell adenomas (BCA) of nasal passages are very rare. It is a pathology of the young adult, with a slight female predominance. In this work we report the observation of a 32-year-old patient, with no particular pathological history who consults for a $3 \mathrm{~cm}$ formation from the right nasal cavity, with purulent secretions whose nasal endoscopy shows a budding lesion of the nasal cavity filling the entire nasal cavity. The CT scan shows a nasal process occupying the right nasal cavity enhancing in a heterogeneous way after injection of contrast product. It has irregular contours after injection, an exerese biopsy of the process was performed, whose anatomopathological study showed a basaloid adenoma.

Keywords: Basal cell adenomas (BCA), cavity, anatomopathological study, CT scan.

Copyright (C) 2021 The Author(s): This is an open-access article distributed under the terms of the Creative Commons Attribution 4.0 International License (CC BY-NC 4.0) which permits unrestricted use, distribution, and reproduction in any medium for non-commercial use provided the original author and source are credited.

\section{INTRODUCTION}

Basal cell adenoma (ACB) is a rare benign tumor of the salivary glands. This tumor proliferation is characterized by its basaloid appearance on the one hand and the absence of myxochondroid stroma characteristic of pleomorphic adenoma on the other hand. We report in this work the case of a patient with a rare location of basaloid adenoma at the nasal level with an atypical clinical manifestation.

\section{CASE REPORT}

32-year-old patient with no pathological history. She presented 6 months prior to her consultation with a right unilateral nasal obstruction that gradually increases, 6 months after the patient noticed the appearance of a reddish formation covered by parts by blackish crusts from the right nasal cavity bleeding on contact with purulent rhinorrheas; without reflex otalgia, adenopathy, and without any notion of altering the general state (Figure-1).

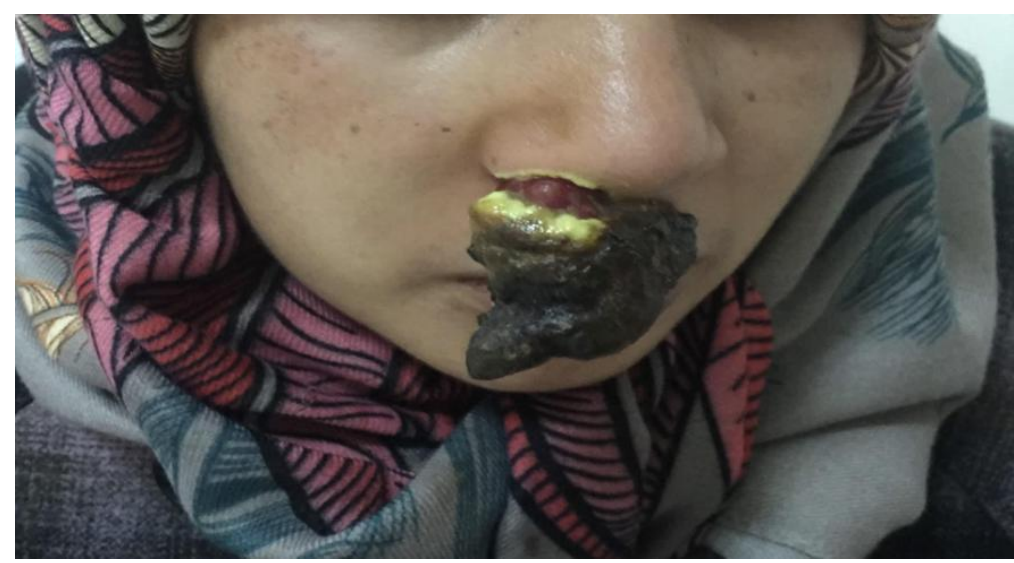

Citation: Najoua. Belhaj et al. Basaloid Adenoma of Nasal Pits: Rare Location with Atypical Clinical Presentation. Sch J Med Case Rep, 2021 Feb 9(2): 120-122. 


\section{Fig-1: Patient picture showed the nasal formation}

Nasal endoscopy showed a process from the budding nasal cavity filling the right nasal pit that does not fill the cavum starting from the nasal septum with no mass effect, the contralateral nasal cavity is without peculiarities.

The injected nasosinusian scan showed a right nasal process occupying the right nasal cavity with irregular contours that overlapped heterogeneously after injection of contrast product without bone lysis (Figure $2 \& 3)$.

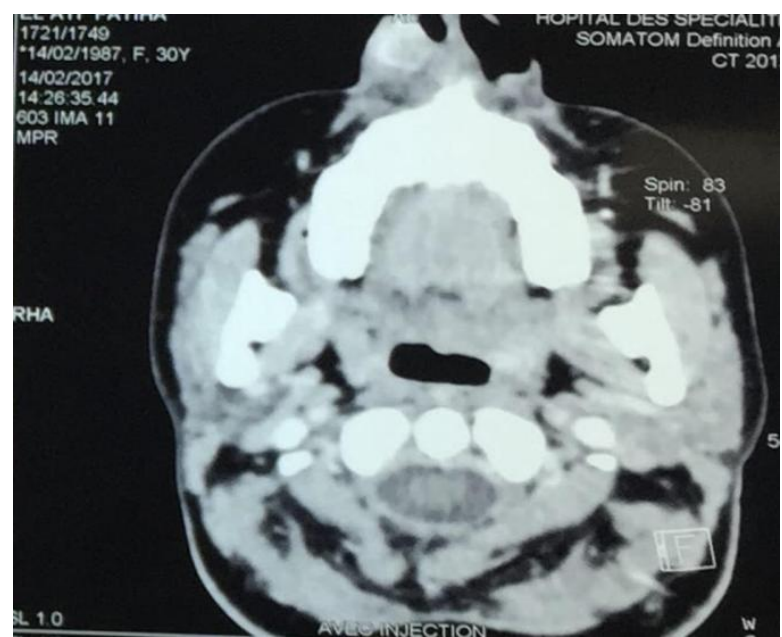

Fig-2: CT scan cuts showing the process of the right nasal cavity

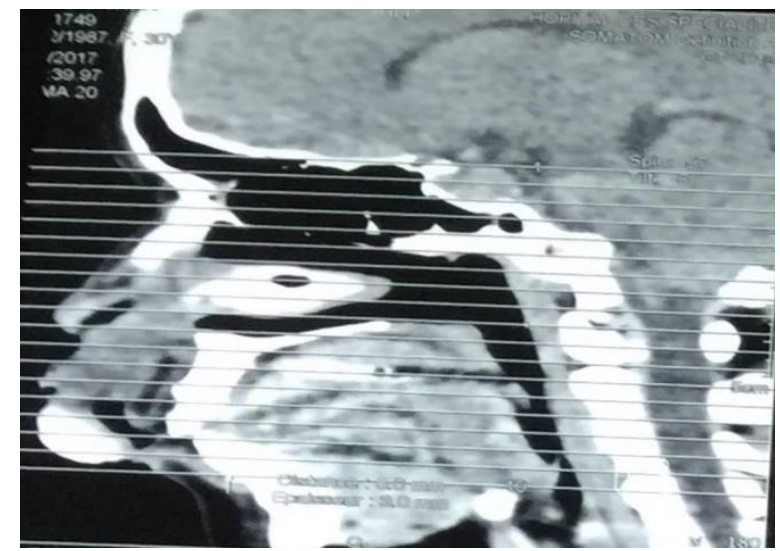

Fig-3: CT scan cuts showing the process of the right nasal cavity

The exeresis biopsy of the entire mass was performed, the piece was referred to the anatomopathological study, the result returned in favor of basaloid adenoma of the nasal pits.

Patient follow-up and endoscopy control every 3 months and then every month over a three-year period did not show a recurrence.

\section{DISCUSSION}

BCAs are rare, accounting for only 1 to $3 \%$ of salivary gland tumors. They are typically found in adults in the 7 th decade with a sex ratio of $2 / 1$ in favor of the female sex. The majority of these tumors reach parotid $(75 \%)$, followed by the submandibular gland (5\%). They are extremely rare in the accessory salivary glands.

Macroscopically, these tumors are small, encapsulated measuring between 1 and $3 \mathrm{~cm}$. The membrane type, on the other hand, can be multinodular and multifocal. Ala cut, they are solid and homogeneous or cystic, white-grey or brown.

The problem of differentiating diagnosis with a malignant tumor type basal cell adenocarcinoma or other malignant tumors, such was the case in our work, especially in the rapid evolution, only the histological study can decide. Histologically, BCAs are composed of eosinophilic cytoplasm basaloid cells with blurred boundaries. Their core is round or oval. These cells create a solid, trabecular, tubular or membrane architecture. The solid type is composed of massifs and islets of varying shape and size surrounded by cubic or cylindrical cells of palisade arrangement. The trabecular type is characterized by spans and cords of basaloid cells separated by a cellular and vascular stroma. The tubular type mainly has ductal structures. The membrane type (as reported) consists of thick hyaline bands separating basaloid cells. These different types can associate and may undergo cystic resurfacing, Malpighian or oncocytic differentiation.

The positivity of tumor cells to cytokeratin, smooth muscle markers, vimentin and p63 indicates a ductal and myoepithelial origin. Some cases of CBA have chromosomal aberrations with a type of Trisomy 8 or translocation. There are two delicate differential diagnostic problems: basal cell adenocarcinoma and smelters adenoma.

Histologically, basal cell adenocarcinoma can be distinguished from CBA by a peripheral invasive component, vascular embolisms, perineal engainement, a greater number of mitosis and tumor necrosis. However, as there is little cellular pleomorphism in basal cell adenocarcinoma, differential diagnosis is difficult on simple biopsy. Immunohistochemical markers are of no help in differential diagnosis $[3,4]$.

\section{Conclusion}

There are several types of benign tumors of the nasal pits and paranasal sinuses, nasal endoscopy and imaging by scanner or MRI can be used to interpret the diagnosis alone the anatomopathological study can confirm it, basaloid adenomas are of very rare location in the nasal pits.

\section{REFERENCES}


1. De Araujo VC. Basal cell adenoma. In; Barnes L, Everson JW, Reichart P, Sidransky D eds. World Health Organization Classification of Tumors. Pathology and genetics of Head and Neck Tumours. Lyon: IARC Press, 2005: 261-2.

2. Sousa SOM, Araujo NS, Correa L, Soubhia AMP, Araujo VC. Immunohistochemical aspects of basal cell adenoma and canalicular adenoma of salivary glands. Oral Oncol. 2001;37:365-8.

3. Nagao T, Sugano I, Ishida $Y$, Hasegawa M, Matsuzaki O, Konno A, Kondo Y, Nagao K. Basal cell adenocarcinoma of the salivary glands: comparison with basal cell adenoma through assessment of cell proliferation, apoptosis, and expression of p53 and bcl- 2. Cancer: Interdisciplinary International Journal of the American Cancer Society. 1998 Feb 1;82(3):43947.

4. Farah-Klibi F, Ferchiou M, Kourda J, EL Amine $\mathrm{O}$, Ferjaoui M. Adénome à cellules basales de type membraneux de la parotide. Tunisie médicale. 2009;87(2):149-51. 